\title{
Process Simulation of Calcium Looping with Indirect Calciner Heat Transfer
}

\author{
Chameera K. Jayarathna ${ }^{1,2}$ Anette Mathisen ${ }^{2}$, Lars Erik $\varnothing \mathrm{i}^{1}$, Lars-André Tokheim ${ }^{1}$ \\ ${ }^{1}$ Telemark University College, Faculty of Technology, Porsgrunn, Norway \\ ${ }^{2}$ Tel-Tek, Research Institute, Porsgrunn, Norway
}

\begin{abstract}
In calcium looping $(\mathrm{CaL})$, calcium oxide $(\mathrm{CaO})$ is used as a sorbent for carbon dioxide $\left(\mathrm{CO}_{2}\right)$. The $\mathrm{CO}_{2}$ reacts with $\mathrm{CaO}$ to produce calcium carbonate $\left(\mathrm{CaCO}_{3}\right)$ in a carbonator. The $\mathrm{CaCO}_{3}$ is then sent to another reactor, a calciner, where the $\mathrm{CaCO}_{3}$ is calcined, producing $\mathrm{CaO}$ (which is returned to the carbonator for another cycle) and more or less pure $\mathrm{CO}_{2}$, which is removed from the system. Conventional $\mathrm{CaL}$ with direct heat transfer using oxy-combustion has an unwanted energy penalty. However, if the heat could be transferred indirectly to the calciner, the energy penalty associated with oxy-combustion could be avoided. In this work, Aspen Plus is used to simulate the $\mathrm{CaL}$ process with indirect heat transfer. The results confirm that such a scheme could give an energy penalty lower than for example amine scrubbing or oxy-combustion.
\end{abstract}

Keywords: Aspen Plus, $\mathrm{CO}_{2}$ capture, energy penalty

\section{Introduction}

Removal of carbon dioxide $\left(\mathrm{CO}_{2}\right)$ from gas streams has been a crucial unit operation for many decades to avoid corrosion and also to improve the calorific value of gas streams. More recently $\mathrm{CO}_{2}$ reduction has become an urgent need due to the greenhouse effect. The average temperature of the earth's atmosphere and ocean is rising continuously. During the last 100 years, the average surface temperature has increased about $0.8^{\circ} \mathrm{C}$ (Choices, 2011). Scientists working on the topic agree that the major cause of the global warming is greenhouse gases emitted due to human activities. Deforestation and burning of fossil fuels are the two main reasons. According to Robinson et al. (Robinson et al., 2007), the total industrial $\mathrm{CO}_{2}$ production, primarily from burning coal, oil and natural gas and the production of cement, is about $8 \mathrm{Gt}$ carbon per year, as reported in 2007. In the last decade, scientific research and knowledge on climate change have progressed considerably and many political efforts have been made to reach worldwide agreement to the Kyoto treaty (UNFCCC, 1998).

The most mature technology for capturing $\mathrm{CO}_{2}$ is using amine-based $\mathrm{CO}_{2}$ solvents to absorb $\mathrm{CO}_{2}$ from the exhaust gas. However, other concepts may be more attractive from an energy penalty point of view. Using a solid sorbent at high temperature is a concept which is now being widely considered as an alternative. Development of more advanced solid sorbents is a continuous process, but a challenge is the high sorbent production cost. $\mathrm{CO}_{2}$ capture from flue gas by calcium looping $(\mathrm{CaL})$ may be an attractive alternative due to the cheap and readily available sorbent (limestone). The calcium looping process, first brought up by Shimizu et al. (Shimizu et al., 1999), is regarded as one of the potential technologies.

In the $\mathrm{CaL}$ process, calcium oxide $(\mathrm{CaO})$ is used as a regenerable solid sorbent to react with $\mathrm{CO}_{2}$. Due to the formation of calcium carbonate in the process, it is also called carbonate looping (Lasheras et al., 2011), or carbonate cycling. Many of the CaL concepts described in the literature (Chang et al., 2013; Kremer et al., 2013; Ströhle et al., 2014; Dieter et al., 2014; Alstom, 2012; Hatzilyberis, 2011; Junk et al., 2013; Junk et al., 2012; Hoeftberger and Karl, 2013) are based on fluidized bed (FB) technology. In $\mathrm{CaL}$, calcium oxide $(\mathrm{CaO})$ reacts with $\mathrm{CO}_{2}$ to form calcium carbonate $\left(\mathrm{CaCO}_{3}\right)$ in a fluidized bed reactor (carbonator) at a temperature around $650^{\circ} \mathrm{C}$, in an exothermic reaction (Bennaceur, 2008):

$$
\begin{gathered}
\mathrm{CaO}(\mathrm{s})+\mathrm{CO}_{2}(\mathrm{~g}) \rightarrow \mathrm{CaCO}_{3}(\mathrm{~s}) \\
\Delta \mathrm{H}_{\mathrm{o}}=-178 \mathrm{~kJ} \mathrm{~mol}^{-1}
\end{gathered}
$$




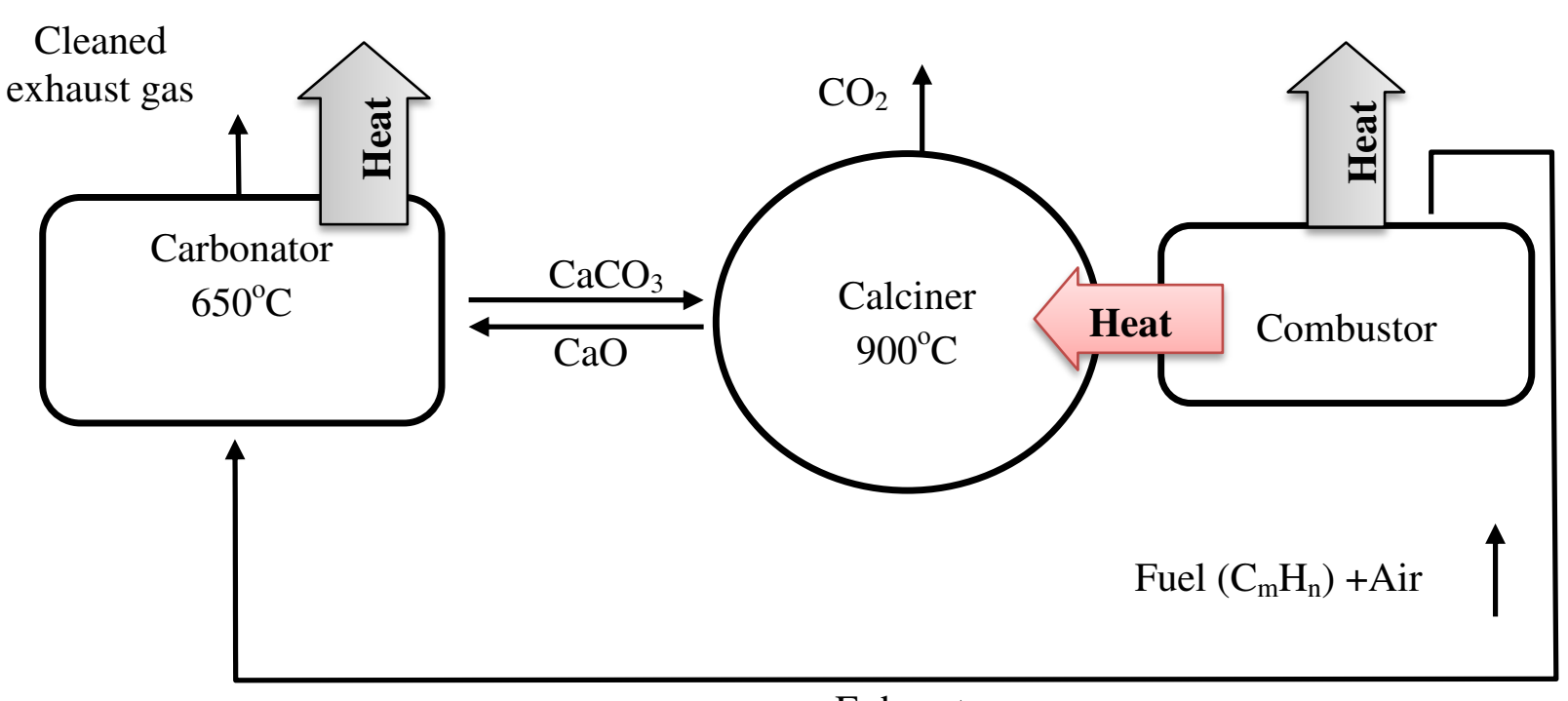

Exhaust gas

Figure 1. Calcium looping cycle with indirect heat transfer between combustor and calciner

The $\mathrm{CaCO}_{3}$ is separated from the cleaned exhaust gas by a gas/solid separator. The cleaned exhaust gas exiting from the carbonator can be released to the atmosphere.

In a second reactor, the calciner, the reverse reaction happen, i.e. $\mathrm{CaCO}_{3}$ decomposes into $\mathrm{CaO}$ and $\mathrm{CO}_{2}$ at a temperature close to $900 \mathrm{C}$. This is an endothermic process, so a significant flow of thermal energy must be supplied to the calciner for the reaction to occur. The regenerated $\mathrm{CaO}$ is separated from the $\mathrm{CO}_{2}$ in a gas/solid separator and recycled back to the carbonator.

In conventional $\mathrm{CaL}$ the heat is transferred directly by oxy-combustion in the calciner; pure oxygen is required as the oxidizer to avoid diluting $\mathrm{CO}_{2}$ with nitrogen. Even though most of the thermal energy supplied in the calciner can be recuperated in the carbonator, the oxycombustion gives an unwanted energy penalty of the CaL technology due to the Air Separation Unit (ASU) which is a key component in the system when it comes to the oxy-combustion.

However, if the heat could be transferred indirectly to the calciner, then the energy penalty associated with oxy-combustion could be avoided, and this would make CaL a much more attractive alternative for the thermal power industry. Since this concept requires extensive integration between the combustor and the calciner, it can be called Fully Integrated Calcium Looping (FICaL). The low energy penalty of $\mathrm{CaL}$ with indirect calciner heat transfer is due to high-temperature integration between the $\mathrm{CO}_{2}$ capture plant and the power plant. The basic idea is illustrated in Figure 1. The fact that the heat transfer takes place at a temperature higher than the typical operational temperature of a coal fired power plant means that the energy penalty usually associated with $\mathrm{CO}_{2}$ capture processes can be significantly reduced.

In this work a coal fired power plant with a FICal-based $\mathrm{CO}_{2}$ capture facility was simulated using Aspen Plus V8.6® software. Three different indirect heat transfer cases were simulated and analyzed. The aim was to determine the impact on the energy balance of the system for each case. The capacity of the power plant was $1890 \mathrm{MW}_{\text {th }}$.

\section{The simulated process}

An overview of the simulated process is given in Figure 2. The three major process units are the calciner, the carbonator and the combustor (coalfired boiler).

Basic coal combustion reactions occur in the combustor, generating $\mathrm{CO}_{2}, \mathrm{H}_{2} \mathrm{O}, \mathrm{SO}_{2}$ and other combustion products. The exhaust is cooled by the combustion air (which is preheated) and dedusted in a filter.

The $\mathrm{CO}_{2}$ in the exhaust gas from the boiler reacts with $\mathrm{CaO}$ in the sorbent to form $\mathrm{CaCO}_{3}$ in the carbonator in an exothermic reaction. The loaded sorbent (rich in $\mathrm{CaCO}_{3}$ ) is separated from the exhaust gas in a cyclone, the clean exhaust gas is vented to the atmosphere via the ID fan and the loaded sorbent is transported to the calciner using steam as the transport medium.

In the calciner, the reverse endothermic reaction takes place with $\mathrm{CO}_{2}$ and $\mathrm{CaO}$ as products. The gas (a mixture of $\mathrm{CO}_{2}$ and steam) is separated from the $\mathrm{CaO}$ in a cyclone. The $\mathrm{CO}_{2}$ 
and steam are then separated in a condenser and the water is preheated to produce steam again for reuse as a transport medium in the calciner. The lean sorbent (rich in $\mathrm{CaO}$ ) is fed back into the carbonator for a new cycle, whereas $\mathrm{CO}_{2}$ is pulled out of the system via another ID fan.

Desulfurization reactions take place at a relatively high temperature in the coal-fired boiler by adding $\mathrm{CaCO}_{3}$ which is calcined in the combustor and reacts with $\mathrm{SO}_{2}$ and $\mathrm{SO}_{3}$ to form $\mathrm{CaSO}_{3}$ and $\mathrm{CaSO}_{4}$, respectively.

$$
\begin{aligned}
& \mathrm{CaO}(\mathrm{s})+\mathrm{SO}_{2}(\mathrm{~g}) \rightarrow \mathrm{CaSO}_{3}(\mathrm{~s}) \\
& \mathrm{CaO}(\mathrm{s})+\mathrm{SO}_{3}(\mathrm{~g}) \rightarrow \mathrm{CaSO}_{4}(\mathrm{~s})
\end{aligned}
$$

Fly ash from the boiler, possibly including some sulfates and sulfites (the part of the sulfates/sulfites not exiting with the bottom-ash), is separated from the boiler exhaust gas in a high-temperature filter.

The following assumptions are made for the reactions in the carbonator,

- $\quad 85 \%$ of the $\mathrm{CO}_{2}$ is captured.

- $18 \%$ of the $\mathrm{CaO}$ in the lean sorbent reacts with $\mathrm{CO}_{2}$ and is converted in to $\mathrm{CaCO}_{3}$, mainly on the surface of the sorbent particles
(Baciocchi et al., 2009). The remaining 82\% exists as an unreacted core not available for reactions due to diffusion limitations.

The energy required for the calcination reaction to occur is transferred indirectly via a tube wall separating the hot combustion gases and the gas/particle suspension in the calciner. Typically, this wall will be the sum of many tube walls, since a large heat transfer area is required. Here, it is assumed that the indirect heat transfer from the combustor to the calciner can be realized without considering material temperature constraints. One way of doing that could be by applying staged combustion, so that the combustion gas temperature is increased in steps in order to maintain the driving force $(\Delta \mathrm{T})$ for the heat transfer. This means that the simulations are based on the assumption that it is possible to transfer enough energy to capture $85 \%$ of the $\mathrm{CO}_{2}$ generated in the boiler.

In principle, all the energy transferred from the boiler is released again in the carbonator, where it is further transferred to the steam cycle, giving no net loss of thermal energy.

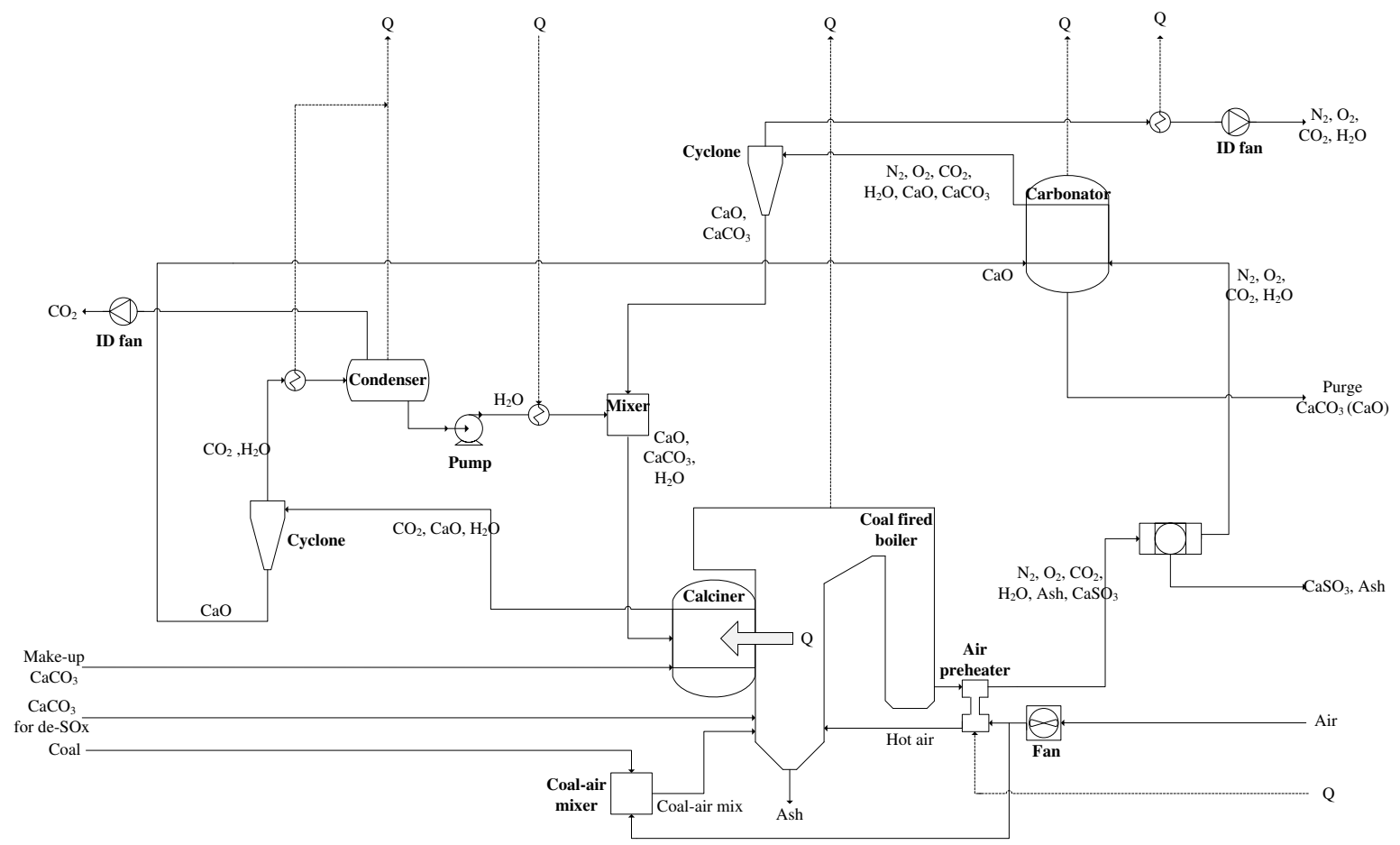

Figure 2. Process flow diagram based on heat transfer concept 


\section{Aspen Plus setup, input parameters and description}

The flow sheet type was chosen with solids and a user defined unit package, allowing for the analysis and results presentation for solid-state input and output streams. The setup of the flow sheet involved assigning the MCINCPSD stream class to the simulation. This allowed fluid streams (MIXED), conventional solid streams with Particle Size Distribution (CIPSD) and nonconventional solid streams with a certain Particle Size Distribution (NCPSD) to be specified. The process type was chosen as COMMON. The IDEAL base calculation method was selected for simplicity and thus phase equilibrium calculations were conducted using Raoult's Law, Henry's Law, ideal gas law, etc.

Coal was modelled as a non-conventional solid based on ultimate, proximate, and sulphur analyses as shown in Table 1. The enthalpy of coal is specified as a user defined value and the density is approximated based on IGT correlations (Aspen Technology, 2012) known as the DCOALIGT model in Aspen Plus. The Particle Size distribution (PSD) of coal was specified as a group of particles with size 25$350 \mu \mathrm{m}$.

Fluid streams were modelled using conventional components using thermophysical data stored in the Aspen Plus databanks. Therefore, no data input were required for these components. The components include: water $\left(\mathrm{H}_{2} \mathrm{O}\right)$, oxygen $\left(\mathrm{O}_{2}\right)$, sulfur dioxide $\left(\mathrm{SO}_{2}\right)$, sulfur trioxide $\left(\mathrm{SO}_{3}\right)$, hydrogen $\left(\mathrm{H}_{2}\right)$, chlorine $\left(\mathrm{Cl}_{2}\right)$, hydrochloric acid $(\mathrm{HCl})$, carbon monoxide $(\mathrm{CO})$ and carbon dioxide $\left(\mathrm{CO}_{2}\right)$. Additionally, solid components were modelled using conventional solids which also have necessary thermophysical data stored in the databanks. The components include: calcium oxide $(\mathrm{CaO})$, calcium carbonate $\left(\mathrm{CaCO}_{3}\right)$, calcium sulfite $\left(\mathrm{CaSO}_{3}\right)$, and calcium sulfate $\left(\mathrm{CaSO}_{4}\right)$. Input values for the Aspen Plus simulations are shown in Table 1. The air preheating temperature is kept as $650{ }^{\circ} \mathrm{C}$.

The Aspen Plus model contains all the main units in the process. The calculation sequence of the units is the same as the process flow. There are two main mass inputs to the process: coal and air to the combustor. In addition, $\mathrm{CaCO}_{3}$ for de- $\mathrm{SO}_{\mathrm{x}}$ is added. The two main outputs are the clean gas and the pure $\mathrm{CO}_{2}$, and in the addition the bottom ash and the fly ash exits from the system. The sorbent $\left(\mathrm{CaO} / \mathrm{CaCO}_{3}\right)$ circulates internally in the system, between the calciner and the carbonator. Makeup and purge streams are not included in the model.
The required $\mathrm{CaO}$ mass flow to the carbonator is calculated in the Aspen Plus model based on the $\mathrm{CO}_{2}$ concentration in the exhaust gas using an Aspen Plus Calculator Block. The required steam mass flow rate is calculated based on the solids mass flow to the calciner using another Calculator Block. The calciner and the carbonator were modelled as stoichiometric conversion reactors, however at temperatures not violating the thermodynamic constraints. Some key assumptions were applied to the simulations as shown below.

- The de-carbonation of $\mathrm{CaCO}_{3}$ in the calciner is $100 \%$ efficient, leaving no uncalcined material in the lean sorbent exiting the calciner.

- The gas-solid separators are $100 \%$ efficient.

- The pressure drop over the carbonator, the calciner, the heat exchangers and gas/solid separators are 110, 150, 10 and 10mbar, respectively.

\subsection{Case 1- Self-fluidization}

In Case 1 (Figure 3) it is assumed that the $\mathrm{CO}_{2}$ developed during calcination is sufficient for fluidization, hence no (or negligible amounts of) steam is used for fluidization. This means there is no need for the condenser, the pump or the water/steam pipelines that would otherwise make up the water/steam loop.

\subsection{Case 2- Steam as the transport medium} In Case 2 (Figure 4) steam is used to fluidize and transport the sorbent particles in the calciner. The steam to $\mathrm{CO}_{2}$ mass ratio at the calciner exit is $1: 1$. The required steam mass flow rate is calculated using a Calculator Block in Aspen Plus. This means that a water/steam loop system is required (there is a small increase in electrical energy consumption due to the condensate pump). Hence, the new features of this system are mixing of steam and particles, cooling of the steam $/ \mathrm{CO}_{2}$ mixture, condensation of steam into water, separation of liquid $\mathrm{H}_{2} \mathrm{O}$ and $\mathrm{CO}_{2}$, pressure increase of liquid $\mathrm{H}_{2} \mathrm{O}$, evaporation of water and reheating of steam. These process units are shown in the upper right area in Figure 4.

\subsection{Case 3- Increased calciner pressure drop}

In Case 3 the system is basically the same as in the reference case (Case 1), but the pressure drop over the calciner is increased to $300 \mathrm{mbar}$. The consequence of this is an increased power consumption of the $\mathrm{CO}_{2}$ fan and slightly higher heat transfer in the $\mathrm{CO}_{2}$ cooling process. 
Table 1. Input values used in the Aspen Plus simulations

\begin{tabular}{|c|c|c|}
\hline Parameter & Value & Unit \\
\hline Thermal power, full-scale & 1890 & $\mathrm{MW}_{\text {th }}$ \\
\hline Fuel & Coal & - \\
\hline Fuel heating value & 27.7 & $\mathrm{MJ} / \mathrm{kg}$ \\
\hline Feed rate of coal in to the combustor & 68.2 & $\mathrm{~kg} / \mathrm{s}$ \\
\hline Excess air & 15 & $\mathrm{wt} \%$ \\
\hline \multicolumn{3}{|l|}{ Fuel ultimate analysis: } \\
\hline $\mathrm{C}$ & 71.7 & $\mathrm{wt} \%$ \\
\hline $\mathrm{H}$ & 3.9 & $\mathrm{wt} \%$ \\
\hline $\mathrm{O}$ & 5.9 & $\mathrm{w} t \%$ \\
\hline $\mathrm{S}$ & 1.2 & $\mathrm{wt} \%$ \\
\hline $\mathrm{N}$ & 1.7 & $\mathrm{wt} \%$ \\
\hline $\mathrm{Cl}$ & 0.1 & $\mathrm{w} t \%$ \\
\hline Ash & 14.3 & $\mathrm{wt} \%$ \\
\hline Moisture & 1.2 & $\mathrm{w} t \%$ \\
\hline \multicolumn{3}{|l|}{ Fuel proximate analysis: } \\
\hline Moisture & 1.2 & $\mathrm{wt} \%$ \\
\hline Volatiles & 23.7 & $\mathrm{wt} \%$ \\
\hline Fixed carbon & 60.8 & $\mathrm{wt} \%$ \\
\hline Ash & 14.3 & $\mathrm{wt} \%$ \\
\hline \multicolumn{3}{|l|}{ Fuel sulfur: } \\
\hline Sulfate & 0.15 & $\mathrm{wt} \%$ \\
\hline Pyritic & 0.90 & $\mathrm{wt} \%$ \\
\hline Organic & 0.15 & $\mathrm{wt} \%$ \\
\hline \multicolumn{3}{|l|}{$\mathrm{CaO} P S D(\mu m)$} \\
\hline$<25$ & 0 & $\mathrm{wt} \%$ \\
\hline $25-50$ & 0.3 & $\mathrm{wt} \%$ \\
\hline $50-100$ & 1.7 & $\mathrm{wt} \%$ \\
\hline $100-150$ & 23.7 & $\mathrm{wt} \%$ \\
\hline $150-200$ & 45.8 & $\mathrm{wt} \%$ \\
\hline $200-350$ & 26.8 & $\mathrm{wt} \%$ \\
\hline $350-500$ & 1.7 & $\mathrm{wt} \%$ \\
\hline Maximum material temperature & 1100 & ${ }^{\circ} \mathrm{C}$ \\
\hline Calcination temperature & $\max 900$ & ${ }^{\circ} \mathrm{C}$ \\
\hline Carbonation temperature & 650 & ${ }^{\circ} \mathrm{C}$ \\
\hline
\end{tabular}




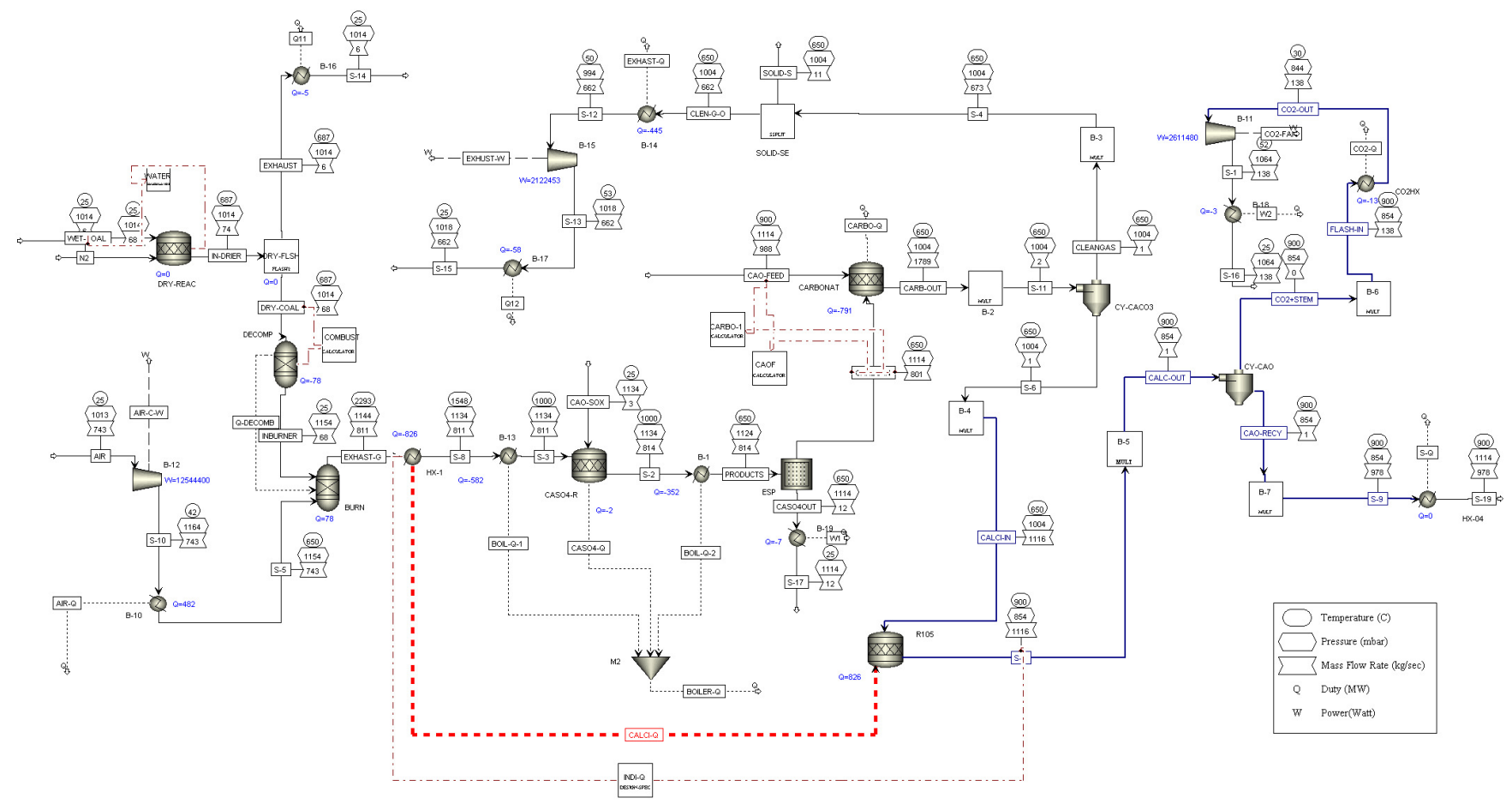

Figure 3. Aspen Plus flow diagram for Case 1 


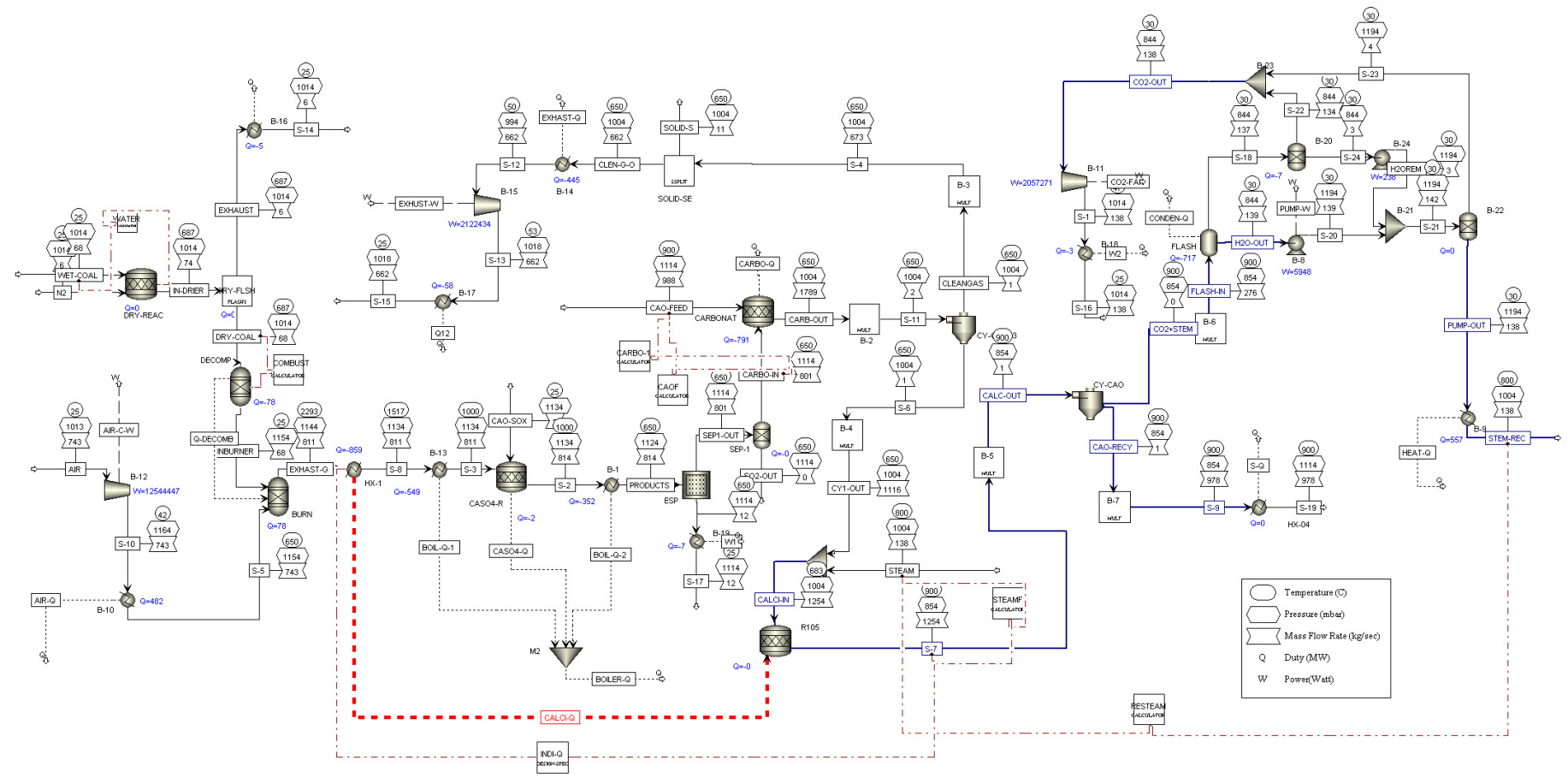

Figure 4. Aspen Plus flow diagram for Case 2 


\section{Energy penalty calculations}

The material balance is given in the form of specified material streams between the equipment units in the Aspen Plus flowsheet. The energy balance is given in the form of energy streams (enthalpy streams of material streams, heat duties or electrical duties) into and out of the equipment units.

The energy penalty of the FICaL system $\left(\Delta \eta_{\text {penalty,FICaL }}\right)$ can be defined as the difference in efficiency between the FICaL process $\left(\eta_{\text {FICaL }}\right)$ and a reference process $\left(\eta_{\text {ref }}\right)$ (in this case a coal-fired power plant without $\mathrm{CO}_{2}$ capture):

$$
\Delta \eta_{\text {penalty,FICaL }}=\eta_{\text {ref }}-\eta_{\text {FICaL }}
$$

The efficiency of the reference plant and the FICaL plant can be calculated as the ratio of the net electrical power produced $\left(\mathrm{E}_{\text {electric,ref }}\right.$ or $\mathrm{E}_{\text {electric,FICaL }}$, respectively) to the thermal energy input $\left(Q_{\text {input }}\right)$, i.e. the coal combustion energy released):

$$
\begin{aligned}
& \eta_{\text {ref }}=\frac{E_{\text {electric,ref }}}{Q_{\text {input }}} \\
& \eta_{\text {FICaL }}=\frac{E_{\text {electric,FICaL }}}{Q_{\text {input }}}
\end{aligned}
$$

The net produced electrical power of a FICaL process is found by subtracting the additional power of the FICaL system $\left(\Delta \mathrm{E}_{\text {electric,FICaL }}\right)$ from the net electrical power of the reference plant:

$$
E_{\text {electric,FICaL }}=E_{\text {electric,ref }}-\Delta E_{\text {electric,FICaL }}
$$

Neglecting any additional heat loss that might result from the FICaL system, the additional FICaL power consumption is mainly due to extra fan power( $\left(E_{\text {fan,FICaL }}-E_{f a n, r e f}\right)$, which in turn is due to increased pressure drop in the carbonator, calciner and cyclones.

$$
\Delta E_{\text {electric,FICaL }}=E_{f a n, F I C a L}-E_{f a n, r e f}
$$

The fan power of the reference plants $\left(\mathrm{E}_{\mathrm{fan}, \mathrm{ref}}\right)$ and the FICaL plant $\left(\mathrm{E}_{\mathrm{fan}, \mathrm{FICaL}}\right)$ may be estimated (assuming isothermal operation) as:

$$
\begin{aligned}
& E_{f a n, r e f}=\frac{\dot{n}_{\text {ref }} R T_{\text {in,ref }}}{\eta_{\text {fan,ref }}} \ln \frac{p_{\text {out }, \text { ref }}}{p_{\text {in }}} \\
& E_{\text {fan,FICaL }}=\frac{\dot{n}_{\text {FIRCaL }} R T_{\text {in,FICaL }}}{\eta_{\text {fan, FICaL }}} \ln \frac{p_{\text {out }, \text { FICaL }}}{p_{\text {in }}}
\end{aligned}
$$

Here, $\dot{n}$ is the gas flow rate $[\mathrm{mol} / \mathrm{s}], \mathrm{R}$ is the universal gas constant $(8.314 \mathrm{~J} / \mathrm{mol} \cdot \mathrm{K}), \eta_{\text {fan }}$ is the fan efficiency, $T_{i n}$ is the gas inlet temperature
$[K]$, and $\mathrm{p}_{\text {in }}$ and $\mathrm{p}_{\text {out }}$ are pressure into and out of the fan $[\mathrm{Pa}]$.

The outlet pressure from the fan $\left(\mathrm{p}_{\text {out,ref }}\right)$ and $\left(\mathrm{p}_{\text {out,FICaL }}\right)$ will be the inlet pressure $\left(\mathrm{p}_{\text {in }}\right)$ plus the total pressure drop that has to be overcome in the process $\left(\Delta \mathrm{p}_{\text {ref }}\right.$ and $\left.\Delta \mathrm{p}_{\mathrm{FICaL}}\right)$ :

$$
\begin{aligned}
& \mathrm{p}_{\text {out }, \text { ref }}=\mathrm{p}_{\text {in }}+\Delta \mathrm{p}_{\text {ref }} \\
& \mathrm{p}_{\text {out }, \text { FICaL }}=\mathrm{p}_{\text {in }}+\Delta \mathrm{p}_{\text {FICaL }}
\end{aligned}
$$

The total gas flow rate in the FICaL system is basically the same as in the reference plant although two fans (the $\mathrm{CO}_{2}$ fan and the ID fan for the cleaned gas) are used instead of one fan (ID fan for the uncleaned exhaust gas). The inlet pressure is also the same and it should be a good assumption to use the same fan efficiencies and the same gas inlet temperature for two systems (with and without $\mathrm{CO}_{2}$ capture).

By combining equations 4.1-4.9, the following, quite simple, equation for the energy penalty of the FICaL system is given:

$$
\Delta \eta_{\text {penalty,FICaL }}=\frac{E_{\text {fan, FICaL }}}{Q}\left[1-\frac{\ln \left(1+\frac{\Delta p_{\text {ref }}}{p_{\text {in }}}\right)}{\ln \left(1+\frac{\Delta p_{F I C a L}}{p_{\text {in }}}\right)}\right]
$$

\section{Results and discussion}

The energy balance, based on the Aspen Plus simulation results, is summarized in Table 2 for these cases. There is a relatively small balance error $(\approx 0.5 \%)$, which may be due to Aspen Plus iterative calculations. However, the error is sufficiently small that the numbers can be used to evaluate the concept.

A reasonable value for the total efficiency (produced electrical power / heat input from the coal feed) for a modern coal based power plant is $40 \%$. With a thermal duty of $1890 \mathrm{MW}$ this gives a total electrical power of $756 \mathrm{MW}$. The estimated energy penalty means that the FICaL plant will, in comparison, have and efficiency of 39.3-39.4\%.

Inclusion of makeup and purge in the system (not accounted for above) will increase the energy penalty. Additional heat loss from the FICaL system is likely to occur due to higher surface area as a result of the extra equipment units, and this will also increase the energy penalty. This contribution is however not included here as its value is unknown. Also, auxiliary equipment potentially requiring some extra electrical energy is not included, but is not likely to be significant.

The pressure drop value of each unit (in particular the calciner and the carbonator) may later be determined more accurately, giving a more accurate energy penalty value. 
Table 2. Energy balance (MW) for Case 1, 2 and 3

\begin{tabular}{|c|c|c|c|c|}
\hline Inputs & AP flowsheet reference & Case 1 & Case 2 & Case 3 \\
\hline $\mathrm{H}_{2} \mathrm{O}$ evaporation + heating & B-9* & 0 & 557 & 0 \\
\hline Air preheating & B-10 & 482 & 482 & 482 \\
\hline Air fan & B-12 & 13 & 13 & 13 \\
\hline Exhaust gas fan & B-15 & 2 & 2 & 2 \\
\hline $\mathrm{CO}_{2}$ fan & B-11 & 3 & 2 & 5 \\
\hline Pump & B-8* & 0 & 0 & 0 \\
\hline Sum inputs & - & 499 & 1054 & 502 \\
\hline \multicolumn{5}{|l|}{ Generation } \\
\hline Coal combustion & - & 1890 & 1890 & 1890 \\
\hline SOx unit & CASO4-R & 2 & 2 & 2 \\
\hline Sum generation & - & 1892 & 1892 & 1892 \\
\hline \multicolumn{5}{|l|}{ Outputs } \\
\hline $\begin{array}{l}\text { Cooling and condensation of } \\
\mathrm{H}_{2} \mathrm{O} / \mathrm{CO}_{2}\end{array}$ & $\begin{array}{c}\text { CO2HX+ FLASH* + } \\
\text { B-20* + B-18 + HX- } \\
04 *\end{array}$ & 137 & 727 & 140 \\
\hline Boiler energy to steam cycle & B-1 + B-13 & 934 & 901 & 934 \\
\hline $\begin{array}{l}\text { Carbonator energy to steam } \\
\text { cycle }\end{array}$ & CARBONAT & 791 & 791 & 791 \\
\hline Hot clean exhaust gas energy & EXHAUST-Q & 445 & 445 & 445 \\
\hline Ash waste heat & B-19 & 7 & 7 & 7 \\
\hline $\begin{array}{l}\text { Cold clean exhaust gas waste } \\
\text { heat }\end{array}$ & B-17 & 58 & 58 & 58 \\
\hline Dryer heat recovery & B-16 & 5 & 5 & 5 \\
\hline $\mathrm{CaO}$ heat recovery & - & 0 & 0 & 0 \\
\hline Sum outputs & - & 2377 & 2934 & 2380 \\
\hline \multicolumn{5}{|l|}{ Energy Penalty } \\
\hline $\begin{array}{l}\text { Energy penalty (reduction in } \\
\text { power plant efficiency) }\end{array}$ & - & $0.6 \%$ & $0.6 \%$ & $0.7 \%$ \\
\hline
\end{tabular}

${ }^{*}$ Contained only in case 2

\section{Conclusions}

Aspen Plus has been used to simulate a $\mathrm{CO}_{2}$ capture plant, fully integrated with a coal-fired power plant. Three different cases were studied and a simplified method was used to estimate the energy penalty. The estimated energy penalty is below $1 \%$ in all cases.

With careful design considerations, the FICaL process is characterized by a very low energy penalty. Even if additional energy consuming effects are included, the FICaL process will likely have a competitive advantage over other technologies.

\section{Acknowledgements}

The authors acknowledge funding from Alstom and Gassnova via the FIRCC project (CLIMIT, 2014) and would like to thank Mr. Michael Balfe from Alstom Power, Germany, for his valuable discussions.

\section{References}

Alstom. Fully Integrated Regenerative Carbonate Cycle (FIRCC), Pre-study description. Alstom, 2012.

Aspen Technology. Aspen Physical Property System. Aspen Technology Inc., MA, USA, 2008.

R. Baciocchi, G. Costa, A. Polettini and R. Pomi: Influence of particle size on the carbonation of stainless steel slag for $\mathrm{CO}_{2}$ storage. Energy Procedia, 1:4859-4866, 2009.

K.G. Bennaceur: $\mathrm{CO}_{2}$ capture and storage a key carbon abatement option [Online]. Paris: OECD/IEA, 2008. Available: http://www.sourceoecd.org/9789264041400.

M.H. Chang, C.M. Huang, W.H. Liu, W.C. Chen, J.Y. Cheng, W. Chen, T.W. WEN, S. Ouyang, C.H. Shen and H.W. HSU: Design and Experimental Investigation of Calcium Looping Process for 3kWth and 1.9-MWth Facilities. Chemical Engineering \& Technology, 36:1525-1532, 2013. 
A.S.C. Choices. Environmental Effects of Increased Atmospheric Carbon Dioxide. The National Academies Press, 15, 2011.

CLIMIT. 226499 - Fully Integrated Regenerative Carbonate Cycle (FIRCC) - Pre study [Online]. Research Council of Norway, 2014. Available: http://www.climit.no/en/projects/developmentproject/226499 [Accessed 26 May 2015].

H. Dieter, A.R. Bidwe, G. Varela-Duelli, A. Charitos, C. Hawthorne and G. Scheffknecht: Development of the calcium looping $\mathrm{CO}_{2}$ capture technology from lab to pilot scale at IFK, University of Stuttgart. Fuel, 127:23-37, 2014.

K.S. Hatzilyberis: Design of an indirect heat rotary kiln gasifier. Fuel Processing Technology, 92:24292454, 2011.

D. Hoeftberger and J. Karl. Self-Fluidization in an Indirectly Heated Calciner: Chemical Engineering \& Technology, 36:1533-1538, 2013.

M. Junk, M. Reitz, J. Ströhle and B. Epple. Thermodynamic evaluation and cold flow model testing of an indirectly heated carbonate looping process. 2nd International Conference on Chemical Looping, Darmstadt, Germany, 2012.

M. Junk, M. Reitz, J. Ströhle and B. Epple: Thermodynamic Evaluation and Cold Flow Model Testing of an Indirectly Heated Carbonate Looping
Process. Chemical Engineering \& Technology, 36:1479-1487, 2013.

J. Kremer, A. Galloy, J. Ströhle and B. Epple: Continuous $\mathrm{CO}_{2}$ Capture in a 1-MWth Carbonate Looping Pilot Plant. Chemical Engineering \& Technology, 36:1518-1524, 2013.

A. Lasheras, J. Ströhle, A. Galloy and B. Epple: Carbonate looping process simulation using a $1 \mathrm{D}$ fluidized bed model for the carbonator. International Journal of Greenhouse Gas Control, 5:686-693, 2011.

A.B. Robinson, N.E. Robinson and W. Soon: Environmental Effects of Increased Atmospheric Carbon Dioxide. Journal of American Physicians and Surgeons, 12:79-90, 2007.

T. Shimizu, T. Hirama, H. Hosada, K. Kitano, M. Inagaki and K. Tejima: A Twin Fluid-Bed Reactor for Removal of $\mathrm{CO}_{2}$ from Combustion Processes. Chemical Engineering Research and Design, 77:6268, 1999.

J. Ströhle, M. Junk, J. Kremer, A. Galloy and B. Epple: Carbonate looping experiments in a $1 \mathrm{MWth}$ pilot plant and model validation. Fuel, 127:13-22, 2014.

UNFCCC. Kyoto Protocol to the United Nations Framework Convention on Climate Change. Review of European Community \& International Environmental Law, 7:214-217, 1998. 